\title{
Carbonized spent bleaching earth as a sorbent for some organic dyes
}

\begin{abstract}
The potential of carbonized spent bleaching earth (CSBE) to remove/reduce acid and basic dyes in aqueous solution was investigated. Results show that CSBE was more effective in removing basic dyes. Parameters like $\mathrm{pH}$, initial concentration, agitation rate, contact time and temperature which affect the sorption process were studied. As determined from Langmuir isotherms the maximum sorption capacities of CSBE for Basic Blue 3 and Methylene Blue were 102.6 and $94.5 \mathrm{mg} / \mathrm{g}$ respectively. Hence CSBE could be a useful sorbent in the treatment of baisc dyes in wastewater.
\end{abstract}

Keyword: Basic dyes; Carbonized spent bleaching earth; Sorption 